\title{
Negative and Neutral Valences of Affective Theory of Mind are More Impaired than Positive Valence in Clinically Stable Schizophrenia Patients
}

\author{
Thammanard Charernboon ${ }^{1,2} \otimes$ \\ ${ }^{1}$ Department of Clinical Epidemiology, Faculty of Medicine, Thammasat University, Pathumthani, Thailand \\ ${ }^{2}$ Center of Excellence in Applied Epidemiology, Thammasat University, Pathumthani, Thailand
}

\begin{abstract}
Objective People with schizophrenia show impairment in social cognition, such as emotion recognition and theory of mind. The current study aims to compare the ability of clinically stable schizophrenia patients to decode the positive, negative and neutral affective
\end{abstract} mental state of others with educational match-paired normal control.

Methods 50 people with schizophrenia and 50 matched controls were compared on the positive, negative and neutral emotional valence of affective theory of mind using the Reading the Mind in the Eyes Tests.

Results The results showed that people with schizophrenia performed worse in negative and neutral emotional valence than normal controls; however, no significant differences in decoding positive valence were found.

Conclusion Our data suggest that there is variability in the performance of affective theory of mind according to emotion valence; the impairments seem to be specific to only negative and neutral emotions, but not positive ones. Psychiatry Investig 2020;17(5):460-464

Key Words Emotion recognition, Schizophrenia, Social cognition, Theory of mind.

\section{INTRODUCTION}

Theory of mind refers to the ability of a person to attribute mental states and feelings to other people; it can generally be divided into cognitive and affective aspects. Cognitive theory of mind refers to the ability to make inferences about others' beliefs and intentions, whereas affective theory of mind corresponds to the ability to infer what a person is feeling. ${ }^{1}$

Affective theory of mind can be assessed by a variety of measures. One standard measurement is the Reading the Mind in the Eyes test (the Eyes test) which evaluates the ability to decode others' complex emotional and mental states using stock photos of people's upper face region. ${ }^{2}$ Several published papers, including multiple meta-analyses, reported people with schizo-

\footnotetext{
Received: February 1, 2020 Revised: March 3, 2020

Accepted: March 9, 2020

$\triangle$ Correspondence: Thammanard Charernboon, $\mathrm{MD}, \mathrm{MSc}, \mathrm{PhD}$ Department of Clinical Epidemiology, Faculty of Medicine, Thammasat University, Phahon Yothin Road, Pathumthani 12120, Thailand

Tel: +66 29269204, E-mail: dr. thammanard@gmail.com

(c) This is an Open Access article distributed under the terms of the Creative Commons Attribution Non-Commercial License (https://creativecommons.org/licenses/bync/4.0) which permits unrestricted non-commercial use, distribution, and reproduction in any medium, provided the original work is properly cited.
}

phrenia demonstrated large magnitudes of deficit in affective theory of mind compared to healthy normal controls. ${ }^{3-5}$

Although many studies have examined the affective theory of mind ability in schizophrenia patients, the specificity of complex emotional decoding deficits is rarely explored. While previous research on facial emotion recognition frequently noted that negative emotion decoding presents with far more deficits than positive emotion decoding, ${ }^{6,7}$ most of this merely focused on basic facial emotion acknowledgement. By only utilizing six basic emotions in these tests, i.e., happiness, anger, disgust, fear, sadness, and surprise, ${ }^{8}$ highly common but complex feelings of subtle affective mental states (e.g., regret, doubt, interest), were not examined. Moreover, among basic states, happiness is the only positive one; therefore, there is a natural imbalance between positive and negative feelings. There is also a concern that identifying happiness, among all the other negative emotions, is relatively easier than differentiating one negative feeling from the others.

In the present study, we use the Eyes test, ${ }^{2}$ which explores beyond basic emotions. Its items can be classified into three emotional valences: negative, positive and neutral. ${ }^{9}$ Our objective was to examine whether the impairment of affective the- 
ory of mind in clinically stable schizophrenia patients varies by emotional valence as compared to the normal controls.

\section{METHODS}

\section{Participants}

Inclusion criteria for both groups were 1) age between 20 to 60 years old 2) Thai literate 3) had at least of 4 years of formal education 4) no major neurological diseases (e.g., stroke), and 5) no history of substance dependences (except for smoking). We recruited 50 patients diagnosed with schizophrenia, according to the Diagnostic and Statistical Manual of Mental Disorders, 5th Edition (DSM-5) criteria by our psychiatrists, at an outpatient mental health clinic, Thammasat University Hospital, Thailand from 1 June 2016 to 31 May 2017. All the schizophrenia patients had received medical treatment for at least 12 weeks and were clinically stable, defined by no significant changes in medical treatment and psychotic symptoms for the last 12 weeks. Schizophrenia patients were matched 1:1 for comparable education with a control group. These 50 normal controls were recruited from relatives or spouses of patients $(78 \%)$ or patients attending the family medicine clinic (22\%: health checkup $12 \%$ and other diagnoses $10 \%)$. They were free of any history of major psychiatric disorder (i.e., schizophrenia, bipolar disorder, major depressive disorder, and intellectual disabilities).

\section{The Reading the Mind in the Eyes (the Eyes)}

A paper version of the Eyes test was used which consists of 36 photos of eyes expressing a variety of complex emotional and mental states. For each photo, a participant has to decide which one of four words best describes what the person in the picture was feeling. Responses are scored 1 or 0 for correctness. Scores range from 0 to 36 , with higher scores indicating better affective theory of mind. ${ }^{2,10}$ Following Harkness et al., ${ }^{9}$ the test items were classified into the three emotional valences of negative, positive and neutral. There were 8 items for positive valence (playful, fantasizing $\times 2$, thoughtful, friendly, interested, flirtatious, and confident), 12 items for negative (upset, worried, regretful, accusing, doubtful, preoccupied, defiant, hostile, cautious, distrustful, nervous, and suspicious), and 16 items for neutral (desire, insisting, uneasy, despondent, preoccupied, cautious, skeptical, anticipating, contemplative, decisive, tentative, pensive, interested, reflective, serious, and concerned).

\section{Procedure}

Characteristics and clinical data were collected from participants; medical records included: age, gender, educational level, duration of illness, number of psychotic episodes, and medications. The doses of antipsychotics were presented as haloper- idol equivalents according to Inada and Inagaki. ${ }^{11}$ The severity of symptoms in schizophrenia patients were rated prior to the Eyes test using the Scale for the Assessment of Positive Symptoms (SAPS) and the Scale for the Assessment of Negative Symptoms (SANS) by a psychiatrist. The SAPS and SANS have global rating scores of $0-20$ and $0-25$, respectively. Higher scores indicate more severe symptoms. ${ }^{12-15}$ Subsequently, the Eyes test was administered by independent research assistants. All participants gave written inform consent, and the study was approved by the Human Ethics Committee of Thammasat University (MTU-EC-ES-6-043/59).

\section{Statistical analysis}

Data were analyzed with STATA v14. Performance of the Eyes test and the sub-score of emotional valences (positive, negative and neutral) were presented by percentages of the correct answers. Between groups' differences were analyzed with independent $\mathrm{t}$-test, and Cohen's effect sized were calculated. Multivariable linear regression analysis was also carried out to examine and adjust the effects of various characteristics.

\section{RESULTS}

Participant characteristic and clinical data are reported in Table 1. There were no significant differences between schizophrenia and normal control groups in age and level of education, but the proportion of female was higher in the normal control group.

The accuracy of the overall score and each emotion valence sub-score are illustrated in Table 2. Schizophrenia patients had significant lower scores than normal controls in total score, negative valence and neutral valence scores; however, no significant differences in decoding positive valence was found. The effect sizes for the differences of negative valence was the largest (1.05), followed by neutral (0.9), with the effect size for positive valence was considerably smaller $(0.34)$.

After controlling for the effects of gender, age, and educational levels, multivariable linear regression analysis confirmed that the schizophrenia group had impairments in negative and neutral valences but not within the positive one (Table 3). Level of education was a significant predictor in all emotional valences, with the exception of the positive one. Age and gender did not influence the performance of all emotional valences.

\section{DISCUSSION}

As previously mentioned, although there is a considerable body of research using the Eyes test to examine the affective theory of mind in people with schizophrenia, ${ }^{3,4}$ very few studies have actually examined whether these impairments var- 
Table 1. Characteristics

\begin{tabular}{|c|c|c|c|}
\hline Variable & Schizophrenia $(\mathrm{N}=50)$ & Normal controls $(\mathrm{N}=50)$ & $\mathrm{p}$-value \\
\hline Gender: female, N (\%) & $28(56)$ & $41(82)$ & 0.009 \\
\hline Age (years), mean (SD) & $37.1(13.2)$ & $36.5(11.2)$ & 0.8 \\
\hline Education (years), mean (SD) & $13.5(3.4)$ & $14.5(4.0)$ & 0.171 \\
\hline Duration of illness (years), mean (SD) & $8.1(9.2)$ & $\mathrm{n} / \mathrm{a}$ & - \\
\hline Number of episodes, N (\%) & & $\mathrm{n} / \mathrm{a}$ & - \\
\hline-1 & $21(42)$ & & \\
\hline$->1$ & $29(58)$ & & \\
\hline Positive symptoms (SAPS), mean (SD) & $2.4(2.4)$ & $\mathrm{n} / \mathrm{a}$ & - \\
\hline Negative symptoms (SANS), mean (SD) & $7.1(4.8)$ & $\mathrm{n} / \mathrm{a}$ & - \\
\hline Typical antipsychotic drugs, $\mathrm{N}(\%)$ & $34(68)$ & $\mathrm{n} / \mathrm{a}$ & - \\
\hline Atypical antipsychotic drugs, N (\%) & $18(36)$ & $\mathrm{n} / \mathrm{a}$ & - \\
\hline Antipsychotic drugs (mg/day, haloperidol equivalent), mean (SD) & $5.3(5.2)$ & $\mathrm{n} / \mathrm{a}$ & - \\
\hline Anticholinergic drugs, N (\%) & $17(34)$ & $\mathrm{n} / \mathrm{a}$ & - \\
\hline
\end{tabular}

n/a: not applicable, SAPS: Scale for the Assessment of Positive Symptoms, SANS: Scale for the Assessment of Negative Symptoms

Table 2. Performance in affective theory of mind test

\begin{tabular}{|c|c|c|c|c|c|}
\hline The eyes test & $\begin{array}{c}\text { Schizophrenia: } \\
\% \text { correct answer (SD) }\end{array}$ & $\begin{array}{c}\text { Normal controls: } \\
\% \text { correct answer (SD) }\end{array}$ & $\%$ difference & $\begin{array}{l}\text { Cohen's d effect size } \\
(95 \% \mathrm{CI})\end{array}$ & p-value \\
\hline Total score & $53.1(11.2)$ & $64.9(11.5)$ & 11.8 & $1.04(0.62-1.45)$ & $<0.001$ \\
\hline Positive valence & $48.3(20.4)$ & $55.3(20.5)$ & 7.0 & $0.34(-0.05-0.74)$ & 0.09 \\
\hline Negative valence & $47.5(16.1)$ & $63.3(13.9)$ & 15.8 & $1.05(0.63-1.47)$ & $<0.001$ \\
\hline Neutral valence & $58.1(14.5)$ & $71.1(14.3)$ & 13.0 & $0.9(0.49-1.31)$ & $<0.001$ \\
\hline
\end{tabular}

Table 3. Multivariable regression analysis of factors predicting performance in social cognition tests

\begin{tabular}{lcc}
\hline \multicolumn{1}{c}{ Variable } & Coefficients & p-value \\
\hline Total score & & \\
Group: schizophrenia & -11.1 & $<0.001$ \\
Gender: female & -2.6 & 0.263 \\
Age & -0.1 & 0.298 \\
Education & 1.4 & $<0.001$ \\
Positive valence & & \\
Group: schizophrenia & -5.0 & 0.238 \\
Gender: female & 3.8 & 0.42 \\
Age & -0.01 & 0.939 \\
Education & 0.9 & 0.144 \\
Negative valence & & \\
Group: schizophrenia & -15.8 & $<0.001$ \\
Gender: female & -5.9 & 0.061 \\
Age & -0.3 & 0.044 \\
Education & 1.4 & $<0.001$ \\
Neutral valence & & $<0.001$ \\
Group: schizophrenia & -11.7 & 0.621 \\
Gender: female & -1.5 & 0.128 \\
Age & -0.2 & \\
Education & 1.5 & \\
\hline
\end{tabular}

ied according to the emotion valences within the test itself. Overall, the present study demonstrated that the healthy controls showed more accuracy in the Eyes scores than schizophrenia patients. This appears to support previous evidence stating schizophrenia patients have impaired affective theory of mind. 3,16

Schizophrenia patients showed large deficits in negative and neutral valences, approximately 1 SD below normal controls. Nonetheless, the level of correctness for positive valence was comparable between patient and control groups. This may highlight that there is significant variability in the performance of affective theory of mind, within emotional valence. These impairments seem to be visible in only negative and neutral emotional perception. Our study concurs with previous research which only used basic facial emotion recognition tasks; even with the deployment of a larger range of emotions, there were far less deficits in positive feeling recognition versus negative. ${ }^{6,717}$ Our results are in line with Tadmor, who also used the Eyes test. Here, it was shown that both first episode and chronic schizophrenia patients performed worse in decoding negative and neutral emotional valances than the control group, yet no differences were observed in positive valence. ${ }^{18}$

There is a consensus agreeing patients with schizophrenia have difficulties decoding the emotion perception of others, 
but there are two hypotheses regarding the nature of these deficits. The first is that the emotional perception impairment is secondary to generalized cognitive impairments, e.g., visuoperceptual ability. The second is that it is a specific deficit in the recognition of emotions. ${ }^{19}$ Our results support the latter hypothesis, as there is a large variation of deficits between negative and positive emotions that can hardly be explained by visuoperceptual problems. Our results also suggest the presence of a separate evaluative system for positive and negative emotional valence..$^{20}$ Though studies have found abnormalities in the brain circuits during emotion processing in patients with schizophrenia, e.g., amygdala, the precise mechanisms responsible for the decoding of each emotion valence are still far from fully understood. ${ }^{21}$ Future studies might focus on the neural mechanism underlying the decoding of each specific emotion.

The present study has several potential clinical implications. It highlights the need to evaluate specific emotion decoding impairments separately. Furthermore, emotional recognition or affective theory of mind training should be focused on negative emotional valences than a positive one.

\section{Strengths and limitations}

One strength of our study is we have used the Eyes test to examine a greater variety of subtle emotional states versus earlier research. We also included healthy controls that matched the schizophrenia patients' level of education, which is usually considered as an important predictor of the Eyes test performance. $^{5}$

In terms of limitations, our patients are not homogeneous in episodes of psychosis; $48 \%$ of them were first-episode psychosis, while the rest were multiple. These two groups might demonstrate a different level of deficits. Secondly, all schizophrenia patients received antipsychotic drugs, so the effects of medication possibly influenced task performance. However, since our inclusion criteria was clinically stable schizophrenia who received treatment for at least 12 weeks, antipsychotic medication was unavoidable. Lastly, the proportion of females in our control group was significantly higher than in the patient group. A meta-analysis of the Eyes test in a healthy population demonstrated a trend of female superiority; therefore, there was a possibility that the higher proportion of females in the control group of our study might magnify the result. However, the difference between gender was small, with an effect size of only 0.17 .22 Moreover, studies comparing schizophrenia patients and healthy controls usually found that there were no significant effects of gender for the Eyes test performances. ${ }^{4,5,23}$ This could be because the effect of disease status is much stronger and might override the effect of gender.

In conclusion, there is a variability in the impairments of affective theory of mind according to emotion valence. The def- icits seem to specific for only negative and neutral emotions, but not positive emotions. Further research is needed to determine why exactly the impairment of positive emotion detection does not occur in schizophrenia patients.

\section{Acknowledgments}

The author would like to thank Tiraya Lerthattasilp, MD and Chananya Suksawatt for their help. This study was supported by a non-restricted educational grant from the Center of Excellence in Applied Epidemiology, Thammasat University.

\section{Conflicts of Interest}

The author has no potential conflicts of interest to disclose.

\section{ORCID iD}

Thammanard Charernboon https://orcid.org/0000-0002-3783-6691

\section{REFERENCES}

1. Shamay-Tsoory SG, Tomer R, Berger BD, Goldsher D, Aharon-Peretz J. Impaired "affective theory of mind" is associated with right ventromedial prefrontal damage. Cogn Behav Neurol 2005;18:55-67.

2. Baron-Cohen S, Wheelwright S, Hill J, Raste Y, Plumb I. The "Reading the Mind in the Eyes" Test revised version: a study with normal adults, and adults with Asperger syndrome or high-functioning autism. J Child Psychol Psychiatry 2001;42:241-251.

3. Bora E, Yucel M, Pantelis C. Theory of mind impairment in schizophrenia: meta-analysis. Schizophr Res 2009;109:1-9.

4. de Achaval D, Costanzo EY, Villarreal M, Jauregui IO, Chiodi A, Castro $\mathrm{MN}$, et al. Emotion processing and theory of mind in schizophrenia patients and their unaffected first-degree relatives. Neuropsychologia 2010;48:1209-1215.

5. Charernboon T, Patumanond J. Social Cognition in Schizophrenia. Ment Illn 2017;9:7054.

6. Mandal MK, Pandey R, Prasad AB. Facial expressions of emotions and schizophrenia: a review. Schizophr Bull 1998;24:399-412.

7. Kohler CG, Bilker W, Hagendoorn M, Gur RE, Gur RC. Emotion recognition deficit in schizophrenia: association with symptomatology and cognition. Biol Psychiatry 2000;48:127-136.

8. Ekman P, Friesen WV. Manual of the Facial Action Coding System (FACS). Palo Alto: Consulting Psychologists Press; 1978.

9. Harkness K, Sabbagh M, Jacobson J, Chowdrey N, Chen T. Enhanced accuracy of mental state decoding in dysphoric college students. Cogn Emot 2005;19:999-1025.

10. Charernboon T, Lerthattasilp T. The Reading the Mind in the Eyes Test: validity and reliability of the Thai Version. Cogn Behav Neurol 2017; 30:98-101.

11. Inada T, Inagaki A. Psychotropic dose equivalence in Japan. Psychiatry Clin Neurosci 2015;69:440-447.

12. Andreasen NC. Scale for the Assessment of Negative Symptoms (SANS). Iowa: Department of Psychiatry, College of Medicine, The University of Iowa; 1984.

13. Andreasen NC. Scale for the Assessment of Positive Symptoms (SAPS). Iowa: University of Iowa Iowa City; 1984.

14. Charernboon T. Preliminary study of the Thai-version of the Scale for the Assessment of Positive Symptoms (SAPS-Thai): content validity, knowngroup validity, and internal consistency reliability. Arch Clin (São Paulo) 2019;46:5-8

15. Charernboon T. Preliminary Study of the Thai Version of the Scale for the Assessment of Negative Symptoms (SANS-Thai). Glob J Health Sci 2019;11:19-24.

16. Brune M. "Theory of mind" in schizophrenia: a review of the literature. Schizophr Bull 2005;31:21-42. 
17. Barkhof E, de Sonneville LMJ, Meijer CJ, de Haan L. Specificity of facial emotion recognition impairments in patients with multi-episode schizophrenia. Schizophr Res Cogn 2015;2:12-19.

18. Tadmor H, Levin M, Dadon T, Meiman ME, Ajameeh A, Mazzawi H, et al. Decoding emotion of the other differs among schizophrenia patients and schizoaffective patients: a pilot study. Schizophr Res Cogn 2016;5:13-20.

19. Kosmidis MH, Bozikas VP, Giannakou M, Anezoulaki D, Fantie BD, Karavatos A. Impaired emotion perception in schizophrenia: a differential deficit. Psychiatry Res 2007;149:279-284.
20. Cacioppo JT, Gardner WL. Emotion. Ann Rev Psychol 1999;50:191-214.

21. Grave J, Soares SC, Martins MJ, Madeira N. Facial emotion processing in schizophrenia: a review of behavioural and neural correlates. Int J Clin Neurosci Ment Health 2017;4(Suppl.3):S06.

22. Kirkland RA, Peterson E, Baker CA, Miller S, Pulos S. Meta-analysis reveals adult female superiority in "Reading the Mind in the Eyes Test". N Am J Psychol 2013;15:121-146.

23. Kettle JW, O'Brien-Simpson L, Allen NB. Impaired theory of mind in first-episode schizophrenia: comparison with community, university and depressed controls. Schizophr Res 2008;99:96-102. 